\title{
Virtual reality interface for HVDC substation and DC breaker design and maintenance
}

\author{
Document Version \\ Accepted author manuscript
}

Link to publication record in Manchester Research Explorer

\section{Citation for published version (APA):}

Marsh, C., Barnes, M., Crowther, B., Watson, S., Vilchis-Rodriguez, D., Carmona Sanchez, J., Shuttleworth, R., Kabbabe, K., Heggo, M., Smith, A. C., \& Pei, X. (2019). Virtual reality interface for HVDC substation and DC breaker design and maintenance. 1-6. Paper presented at IET AC/DC Conference, Coventry, United Kingdom.

\section{Citing this paper}

Please note that where the full-text provided on Manchester Research Explorer is the Author Accepted Manuscript or Proof version this may differ from the final Published version. If citing, it is advised that you check and use the publisher's definitive version.

\section{General rights}

Copyright and moral rights for the publications made accessible in the Research Explorer are retained by the authors and/or other copyright owners and it is a condition of accessing publications that users recognise and abide by the legal requirements associated with these rights.

\section{Takedown policy}

If you believe that this document breaches copyright please refer to the University of Manchester's Takedown Procedures [http://man.ac.uk/04Y6Bo] or contact uml.scholarlycommunications@manchester.ac.uk providing relevant details, so we can investigate your claim.

\section{OPEN ACCESS}




\title{
Virtual Reality Interface for HVDC Substation and DC Breaker Design and Maintenance
}

\author{
C Marsh*, M Barnes*, W Crowther*, S Watson*, X Pei ${ }^{\dagger}$, D Vilchis-Rodriguez*, J Carmona*, R \\ Shuttleworth*, K Kabbabe*, M Heggo*, AC Smith*
}

*University of Manchester, UK, email: mike.barnes@manchester.ac.uk, ${ }^{\dagger}$ University of Bath, UK

\begin{abstract}
Keywords: Virtual Reality, HVDC, DC Breaker, Maintenance

Abstract

For HVDC links, the substation is a major cost factor. 3D visualization using virtual reality has the potential to play a significant part in cost reduction. This paper outlines the problem and gives two examples: the use of visualization for planning internal drone inspection; and the application of visualization to the design of a superconducting fault-current limiter breaker.
\end{abstract}

\section{Introduction}

The use of visualization is of increasing importance in a variety of fields from city planning to transportation. Historically this visualization has been two dimensional, and Computer Aided Design (CAD) has been used extensively for design of systems to limit electric field strength, for the design of cooling systems, etc, with a focus on subassemblies rather than the whole system. Such two dimensional system models as have been developed have been 'virtual tours': intended for public information, marketing and visual environment impact assessment [1-3].

Research into three-dimensional visualization (3DV) has been on-going for 20 years [4], including '3D' training simulators for offshore wind turbines (eg Vestas). Despite the video games industry making several forays into the commercial market in this time, it is only recently that a combination of visualization, control and processing has become available to allow widespread uptake. Resulting products and hardware developed for the computer games industry are now finding application elsewhere, and 3DV tools were shown by several manufacturers for offshore windfarms, HVDC and other plant at the Cigré 2018 meeting in Paris.

In the UK and Europe ambitious plans exist for offshore wind development, for many of which HVDC is the preferred connection option, with further links planned to Europe and embedded in the UK network [5]. Optimizing the layout of the plant in terms of space saving, enabling incorporation of future technology, and access for maintenance and safety is increasingly important: and it is here that the increased use of $3 \mathrm{DV}$ could play a major part. This paper will discuss the current state of the art of 3DV technology in section 2 and then examine two applications.

\section{Three Dimensional Visualization}

Three-dimensional visualization (3DV) is the generic term for using computer generated models of objects having height, width and depth to create imagery or footage for the communication of various concepts, including design ideas and plans during project planning and execution stages. 3DVs can also be used to communicate abstract variables and design constraints, for example, the required clearance between electrical components may be calculated by engineers and displayed as translucent areas around electrical component models Figure 1.

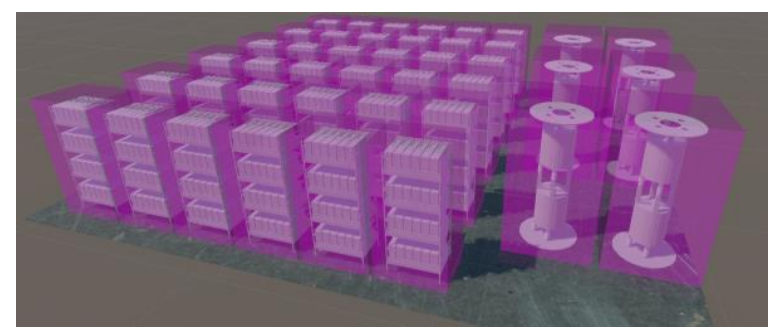

Figure 1: Clearance constraint visualised (purple) for electrical components (grey)

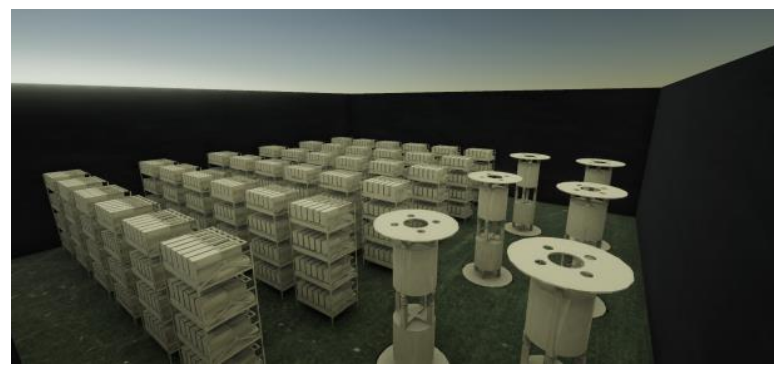

Figure 2: Still images or animations allowing different perspective views to be shown

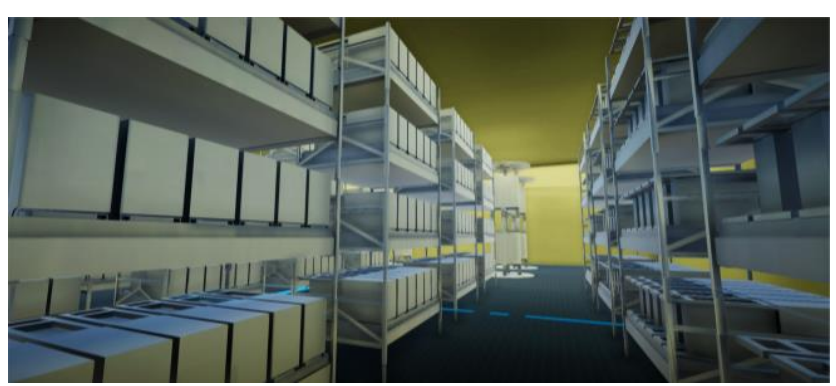

Figure 3: Walk-throughs of a scene rendered as a video or for Virtual or Augmented Reality 
Many software packages exist for the development and rendering of 3D models, a review of such software has been conducted by Miller et al [6]. 3DVs may be presented in various ways, as shown in Figures 2 and 3.

3DV requires a combination of perception (often a stereoscopic headpiece) and interaction with the environment (through controllers) in order to achieve reasonable embodiment (the degree to which the user is collocated with interaction effects visually and spatially). The effectiveness of 3DV over conventional 2D displays has been evaluated by multiple studies ([7] and [8] give a summary). In general, for visualizations of densely grouped objects, where relative position visualisation is important and a high degree of interaction / immersion is required, 3DV systems have advantages. For other factors, 2D visualisation can be better, e.g. understanding of relative positions and precise measurement. $3 \mathrm{DV}$ is complex, and interaction tools for 3DV are still under development [7].

\subsection{Virtual Reality}

$3 \mathrm{DV}$ s which are output to $2 \mathrm{D}$ displays require some abstraction to represent the third dimension which must be understood and converted into a $3 \mathrm{D}$ interpretation by the viewer. One way to overcome the need for abstraction is to render two views of a visualisation as though they were seen one from each eye of the viewer. The displays are then shown to their respective eyes, enabling 3D stereoscopic vision and therefore depth perception. Virtual Reality (VR) is a phrase often connected with the use of a stereoscopic Head Mounted Display (HMD) which uses tracked orientation and position information to determine what the user of the HMD is facing, and therefore what to display to the user to entirely immerse them in a virtual environment, or reality. Tracked controllers or haptic gloves may be provided which allow the user to interact with the virtual environment.

VR is not a new method or technology; the first stereoscopic television display was patented in 1960 [9]. For a long time however, VR has been limited by the sheer computing power required to render two high resolution displays at a comfortable frame rate. A person is likely to experience motion sickness in a VR simulation with low frame rate as the user's 'vision' will not update quickly enough to match the movement of their head [10]. Similarly, a high resolution is required to properly fill the user's field of view while maintaining a clear image. High resolution and high refresh rates require high computing power which, until recent years, has been a luxury available only to those with access to supercomputers. With capable and affordable Graphics Processing Units and recent hardware developments made by Oculus, HTC, Samsung and other companies, VR is now commercially accessible.

Similar in effect to motion sickness, cyber-sickness is caused by a person seeing motion but not experiencing the sensation of movement in their muscles or balance mechanisms. This can be induced by translating a person through any virtual environment and can be incredibly nauseating. The issue of cyber-sickness is generally overcome by allowing users to walk, either in their workspace or on an omnidirectional treadmill, and tracking their movement, updating the environment appropriately. Where space or treadmills are not accessible, users can be teleported via 'instantaneous' jumps around the virtual environment to prevent their experience of motion.

VR's immersive effect is used in training simulations to provide a safe replica of scenarios where the operation environment is unsafe or hard to reach, such as in the military [11] and there are obvious offshore applications. As well as training, VR's use is being applied in the field of robotics as a teleoperation tool: VR is particularly useful for providing operators with both egocentric and exocentric views during robotic operations [12, 13]. Tools such as Microsoft Layout [14] were developed to assist in prototyping of building and room layouts. The user is provided with the ability to arrange components within a virtual representation of the proposed area, allowing for interactive decision making without the need to move physical components.

\subsection{Augmented Reality}

While VR provides the user with an entirely virtual interface, which is suitable for tasks such as teleoperation and design prototype visualizations, some tasks are better performed when the user is able to see a combination of the real world and 3DVs. This enhancing of reality is termed Augmented Reality (AR). AR may be achieved in various ways. The user may have their view of the world overlaid with 2D Computer Generated Images (CGI) to provide additional information, sometimes using forced perspective to 'fit' the visualizations into the real world, other times overlaying flat labels similar to a Heads Up Display often seen in video games. This method is possible with a standard camera and rendering software. Microsoft's Hololens [15] uses spatial information such as LiDAR data and tracking similar to that of a VR HMD to size and place 3D models into the real world. The user is given a see-through headset which renders stereoscopic holographic images to give the perception of depth and more convincingly 'fit' visualizations into reality.

AR brings the ability to combine information from multiple sources and real world context and is being used by companies such as Ford and Volvo during design stages to provide "faster iteration" and "clearer communication of a design theme" [16]. Companies such as True View Visuals offer the ability to superimpose proposed designs in AR videos which can be shown to stakeholders for projects such as wind and solar farm development [17].

\section{Substation Layout for Drone Inspection}

HVDC converter stations are equipped with different fixedpoint systems for continuous monitoring, such as the valvebased electronics (VBE) unit and the thyristor triggering and monitoring (TTM) unit [18] in current source systems. These 
monitoring devices help in identifying the failed parts in a thyristor module which need replacement. Leak detectors and arrester monitors also help in monitoring the cooling system and overvoltage conditions caused by lightning strike or electrostatic discharge. For large-scale substations, lots of fixed-point sensors are required. The drawbacks of using them are limited sensing modalities, large data rates and the fact that further onsite human analysis is often required to fully understand the cause of the fault. For voltage source HVDC connected offshore wind farms in the future, this approach may not be the most cost-efficient solution, which has led to the concept of using remotely operated or autonomous mobile sensor platforms to help identify and characterise faults. Drones are being considered for HVDC converter hall inspection as they do not introduce any direct contact with hall ground or walls and do not require any additional installations to work. However, interference from the high electromagnetic field nature of the converter stations represents a challenge to the reliable operation of the drones.

Based on data available for a typical $800 \mathrm{kV}$ (current source) converter station, valves are typically rated to $7.2 \mathrm{kV}$ and 6.25 $\mathrm{kA}$ [18]. Preserving a sufficient air clearance distance between valve towers is a key factor in substation layout design to avoid possible air breakdown [19]. The electric field strength in an $800 \mathrm{kV}$ converter station is reported to reach a maximum value of $1271 \mathrm{~V} / \mathrm{mm}$ [20], while the magnetic field can reach up to $2 \mathrm{mT}$ for the same station [21], in the presence of proper shielding mechanisms. However, if a fault occurs, the inspection drone may be required to approach areas with electric and magnetic fields beyond their nominal values.

Corona discharge can interfere with the communication and control signals inside the drone, causing abnormal navigation behaviour. According to the simulation of a quadcopter model inside a high electric field environment, the most vulnerable parts in the drone to corona discharge are the motors and the autopilot as illustrated in Figure 4. Drones are also susceptible to exposure to high magnetic fields (EMI) with respect to the motor control and magnetometer. Conventional drones rely primarily on small brushless DC (BLDC) motors, which are controlled using electronic speed controllers (ESC). However, exposing those small motors to high magnetic field can cause the ESC to operate incorrectly and affect the overall drone navigation. Converter halls are a global positioning system (GPS) denied, dark environment, which means that traditional drone localization and object avoidance using GPS or visual sensors is not feasible. The use of magnetometers is also precluded due to the high magnetic fields and ferromagnetic content.

For drone inspections of converter halls, 3D visualisation environments can be used for two purposes; simulation and operation. In the simulation stage, realistic models can be developed in CAD software and imported into simulators such as Gazebo or Unity as shown in Figure 5. Navigation algorithms can then be assessed before being implemented on the real platforms.
The second way 3D visualisation can be used is in the operation of the drones. Human-Robot-Interaction (HRI) for mobile robots is a growing area of research [22]. Controlling real-world robots whist in a VR environment (Mixed Reality control) is currently being investigated [23]. Operators could move around the virtual representation of the real world and observe real-time sensor data overlaid in the VR world. They could then task single or multiple robots to take readings, measurements or visual scans to augment the fixed-point data.

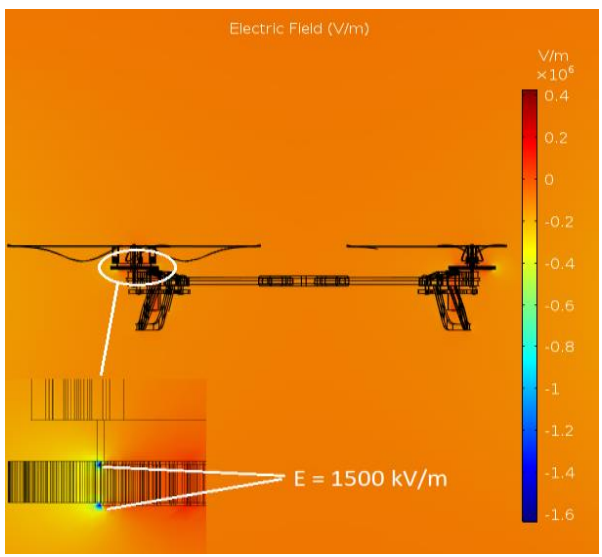

Figure 4: COMSOL simulation of electric field strengths on a drone in a HV environment. The vertical lines indicate the slices of the motor CAD model used in the simulation.

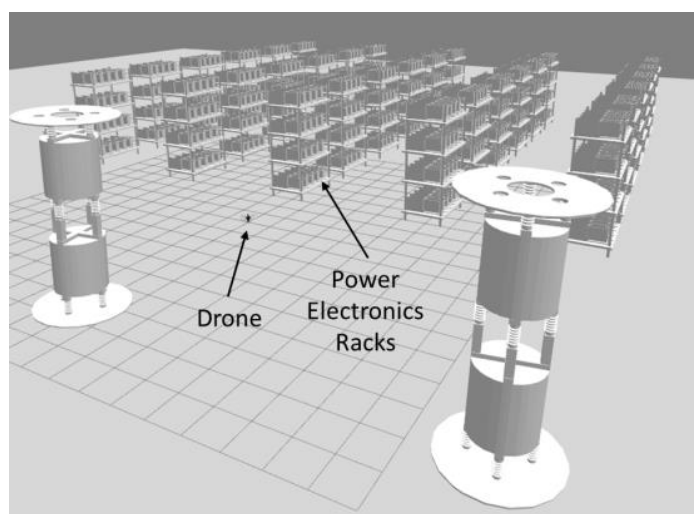

Figure 5: Gazebo 3D simulation environment of a drone in a HVDC power electronics hall

\section{HVDC Breaker Design}

A further application of VR is derisking future technology: this is both for its design and maintenance (especially if part of the maintenance is undertaken by a new technology like drone-based condition monitoring). As an example, to ensure high availability in multi-terminal HVDC systems (MTDC), DC circuit breakers (CBs) will be necessary: DC faults can be isolated by DCCBs to avoid the shutdown of the whole DC grid, enhancing the reliability of power supply. HVDC-CBs are currently at a research stage, with a multitude of topologies proposed [24-28]. Such breakers should provide a breaking time of less than $2 \mathrm{~ms}$ and a conduction loss of less than $0.1 \%$ [29]. Compactness of design is also highly desirable. Purely mechanical CBs for DC protection have been suggested $[27,28]$, but are generally considered too 
slow for MTDC. Hybrid DC-CB topologies show promise. Typically they have a normal conduction branch, an interrupting branch and an energy dissipation branch. The mechanism used to achieve DC current interruption differs drastically between CB designs. For instance, the Proactive $\mathrm{CB}$ (Figure 6a) produces a back electromotive force (EMF) of enough magnitude to commute the fault current to the main breaker by turning off the auxiliary DC breaker on the normal current path. Once current commutation is achieved, the fast disconnector is opened with no electric arc, creating a galvanic barrier over the normal conduction path. Then the main solid-state breaker is turned off, isolating the fault. The remaining energy is dissipated by the metal oxide varistor (MOV) on the energy dissipation branch. In this design the current limiting reactor is used to reduce the rise of fault current, further protecting the system electronic components.

In a recent variant [25], Figure $6 \mathrm{~b}$, a resistive (Rsc) type superconducting fault current limiter (SFCL) is used to commute the fault current to the main breaker. When fault current exceeds the superconductor quench current, the superconductor in the SFCL-CB increases its resistance by several orders of magnitude, deviating fault current to the relatively low impedance main breaker path. Once current commutation is achieved, the steps to achieve current interruption are similar to that of the proactive breaker. One important difference between the proactive and SFCL-CB designs is that the presence of the SFCL obviates the need for a limiting reactor. In addition, no conduction losses are incurred on the SFCL-CB by the presence of the commutating element, although cryogenic cooling is required for the SFCL operation.

(a)

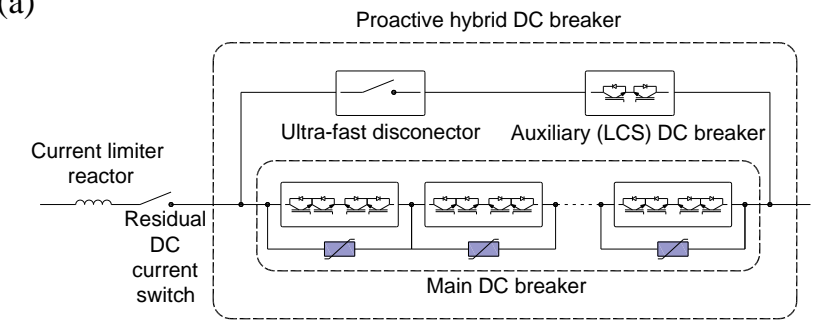

(b)

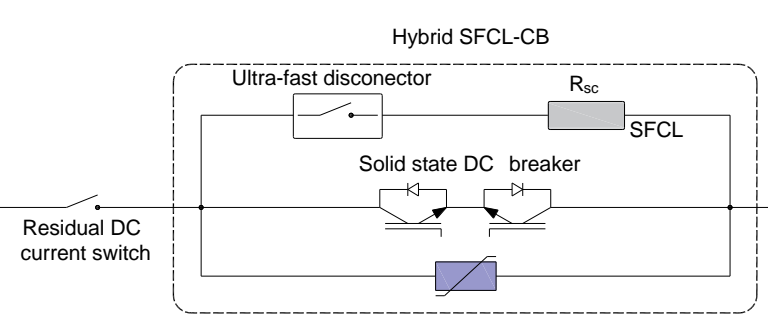

Figure 6: Hybrid HVDC-CB topologies: (a) Proactive CB [24], (b) SFCL-CB [25]

Given the multiplicity of components needed for DC circuit breakers, the newness of the technology, and the space constraints they would be required to meet for offshore application in multi-terminal DC grids: layout and maintenance planning become a key requirement. Here 3DV has an important part to play in order to combine inputs from all design teams and the inspections and maintenance providers. Formulating a $3 \mathrm{DV}$ model therefore requires obtaining precise information from a number of stakeholders.

It is expected that that for redundancy and simplicity HVDCCBs will have a modular design. Thus a number of series connected modules will be used to accommodate different voltage levels. For compactness, a gas insulated switchgear (GIS) system coupling a switch with a compact, ultra-fast, electromechanical actuator would be expected to be used as the mechanical element. Given the number of IGBTs required by the proactive and SFCL-CB, an important portion of these $\mathrm{CBs}$ volume will be occupied for this arrangement. For the SFCL-CB additional volume will be required to accommodate the SFCL module. The SFCL is usually enclosed in a cylindrical container; the size of the container would depend entirely on the CB voltage and current ratings. In addition, the space occupied and the complexity of the ancillaries associated with any CB (such as power supply, temporary energy storage and cooling system) must be also considered when selecting a CB topology.

Given the complexities of different breaker designs, assessing their space requirement in an HVDC station becomes difficult - especially given the as yet unspecified final designs of some components (the cryostat containing the SFCL in the SFCL$\mathrm{CB}$ design for example). Given the constrained space in an offshore substation, multiple factors need assessing: space required for access, maintenance, assessing the ease with which regular inspection can be carried out (possibly by drone), the space needed for lifting equipment for subcomponents and access paths for sub-assemblies. Thus the people undertaking inspection and maintenance need to be consulted by the original system design team early in the design process. Being able to walk maintenance engineers through a virtual substation and assess the relatively impacts of different configurations thus becomes critical.

For example consider a visualisation of the superconducting HVDC breaker, Figure 7 which has been designed in Blender with rendering and arranging done using Unity.

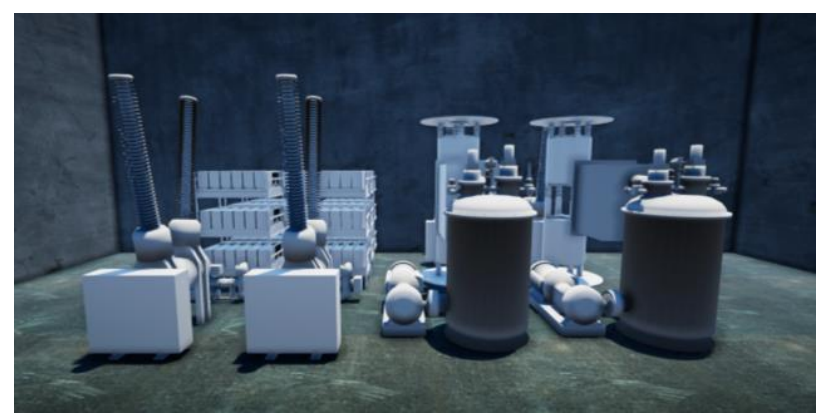

Figure 7: Visualisation of HVDC Breaker

The superconducting elements need to be housed in a cryostat with cooling plant, and at the high voltages under consideration, this makes it potentially the largest breaker component. Locating and sizing this becomes critical not only for footprint of the breaker, access and maintenance, but also 
for the sizing and layout of the civil engineering (housing). Visualization has been used to design resistive SFCL layout, for example, Applied Materials used animation to demonstrate the structure of a $115 \mathrm{kV}$ AC SFCL [30]. The resistive SFCL unit consists the following key components: superconducting coil, cryostat, cryo-cooler compressor, water chiller and vacuum pump. This can also be used to examine design trade-offs.

Presently, yttrium barium copper oxide (YBCO) and magnesium diboride $\left(\mathrm{MgB}_{2}\right)$ superconductor tapes are used for SFCL application. The total length of superconducting tape required for SFCL depends on the HVDC system voltage. The maximum electric field for commercial available YBCO tape is limited to $50 \mathrm{~V} / \mathrm{m}$. Advanced superconducting tape is under development, which aims to increase the electric field higher than $100 \mathrm{~V} / \mathrm{m}[31,32]$. This has great potential to significantly reduce the total length of superconducting tape needed for HVDC SFCL application. A YBCO superconducting coil normally uses a pancake coil structure because it is the most compact structure for the same length of superconducting tape. Many pancake coils are mechanically coupled to a stack and connected in series for high voltage application [33]. $\mathrm{A} \mathrm{MgB}_{2}$ superconducting coil is normally wound in a solenoidal coil form. As shown in Figure 8, two solenoidal $\mathrm{MgB} 2$ coil are connected in series for an (AC) $11 \mathrm{kV}$ SFCL.

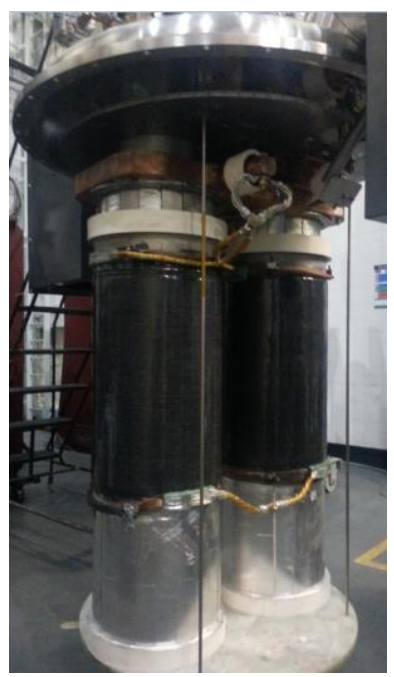

Figure 8: $11 \mathrm{kV}$ SFCL coil using $\mathrm{MgB}_{2}$ superconductor at University of Manchester

The superconducting coils are usually enclosed in a cylindrical cryostat, the size of the cryostat is highly dependent on the voltage level of the HVDC system. The cryo-cooler compressor and associated water chiller are generally rectangular cuboid in shape. The compressor is linked with cold head within the cryostat through helium flex lines. A vacuum pump is used to provide good vacuum insulation for the cryostat so that the cryostat can maintain low operating temperature for the superconducting coil. Obtaining a layout which marries electrical with plumbing requirements will benefit from $3 \mathrm{DV}$.
The size of the current leads for the cryostat depends on the current rating, and the size of the bushings depends on the system voltage. The cylindrical cryostat might be very high due to a large number of pancake coils connected in series for HVDC application. The cylindrical cryostat can be placed vertically rather than horizontally for maintenance purposes or space constraints. The final layout is thus a tradeoff between voltage isolation, maintenance and civil engineering requirements. Since these are disparate disciplines having a common framework/tool for discussion between project teams is essential.

While 3DV allows a number of ideas and layouts to be easily trialled, care should be taken: $3 \mathrm{DV}$ s represent approximations with crisp precision, and the compelling nature of the visualisation can seduce the viewer into attributing greater accuracy than is warranted. A final numerical value of footprint can be hard to quantify: the inherently precise nature of the design tool means the 'garbage-in garbage-out' principle applies. However for much the same reasons $3 \mathrm{DV}$ is exceptionally good at provoking discussions: in our 3DV process for the SFCL breaker, the interaction engendered among different members of the team who had to provide specifications, and could see the effects on each other's components, was valuable and sparked useful and provocative discussions.

\section{Conclusions}

$3 \mathrm{DV}$ is a rapidly developing field which is benefitting considerably from technology from the computer games industry. Visualizations of complex systems requiring a multiplicity of spatial perspectives particularly benefit from a 3DV treatment. New applications continue to be found in the realms of design, maintenance, planning and mixed reality control. As the technology progresses further, applications will undoubtedly emerge, though 3DV must be treated with caution: the validity of output is only as good as the validity of the input for the purpose under consideration. Lastly 2D visualization will remain the best option for many purposes.

\section{Acknowldgements}

The authors would like to acknowledge the support of EPSRC grants EP/L021552/1 and EP/P009743/1.

\section{References}

[1] Camgen Marketing, "ABB Refinery Tour: Tanks to Substation", $\quad 6^{\text {th }} \quad$ April 2016, https://www.youtube.com/watch?v=elfnCacy5ug

[2] Bentley Reality Modelling, "360 Degree Virtual Reality: Substation", $28^{\text {th }} \quad$ November 2017 , https://www.youtube.com/watch?v=Po5O2bqri6U

[3] TenneT, "Connecting offshore wind energy to the grid DolWin3", $\quad 14^{\text {th }} \quad$ February 2016, https://www.youtube.com/watch?v=Zy2k-Zc5xPE 
[4] J. J. LaViola, "Bringing VR and Spatial 3D Interaction to the Masses through Video Games," IEEE Computer Graphics and Applications, vol. 28, no. 5, pp. 10-15, (2008). doi: 10.1109/MCG.2008.92

[5] M. Barnes, D. Van Hertem, S.P. Teeuwsen, and M. Callavik, "HVDC Systems in Smart Grids", IEEE Proceedings, vol. 105, no. 11, (2017), doi: 10.1109/JPROC.2017.2672879

[6] D. Miller, J. Morrice, M. McKeen, G. Donaldson-Selby, C. Wang, and J. Munoz-Rojas, "Use of digital and 3D visualisation technology in planning for new development," Rep. Scottish Gov., p. 109, (2016).

[7] B. Bach, R. Sicat, J. Beyer, M. Cordeil, and H. Pfister, "The Hologram in My Hand: How Effective is Interactive Exploration of 3D Visualizations in Immersive Tangible Augmented Reality?," IEEE Transactions on Visualization and Computer Graphics, vol. 24, no. 1, pp. 457-467, (2018). doi: 10.1109/TVCG.2017.2745941

[8] S. Dübel, M. Röhlig, H. Schumann, and M. Trapp, "2D and 3D presentation of spatial data: A systematic review," in 2014 IEEE VIS International Workshop on 3DVis (3DVis), (2014), pp. 11-18.

[9] M. L. Heilig, "Stereoscopic-Television apparatus for Individual Use," 2995156, 1960.

[10] W. Reed, "Medical Aspects of Harsh Environments Volume 2," Washington DC, 2002.

[11] Unimersiv, "How the Military is Incorporating Virtual Reality into Troop Training," 2016. [Online]. Available: https://unimersiv.com/military-incorporating-vr-trooptraining/. [Accessed: 15-Aug-2018].

[12] J. Allspaw, J. Roche, N. Lemiesz, M. Yannuzzi, and H. A. Yanco, "Remotely Teleoperating a Humanoid Robot to Perform Fine Motor Tasks with Virtual Reality," WM2018 Conference, (2018).

[13]. Ferland, F. Pomerleau, C. T. Le Dinh, and F. Michaud, "Egocentric and exocentric teleoperation interface using real-time, 3D video projection," Proc. 4th ACM/IEEE Int. Conf. Hum. Robot Interact. (2009).

[14] "Microsoft Layout." [Online]. Available: https://www.microsoft.com/en-gb/p/microsoft-layoutpreview/9nsjn53k3gfj. [Accessed: 17-Aug-2018].

[15] "Microsoft HoloLens." [Online]. Available: https://www.microsoft.com/en-us/hololens. [Accessed: 17-Aug-2018].

[16] "Unleash Business Innovation with Holographic Technology | Microsoft HoloLens.” [Online]. Available: https://www.microsoft.com/en-us/hololens/commercialoverview\#. [Accessed: 17-Aug-2018].

[17] "True View Visuals." [Online]. Available: http://trueviewvisuals.com/. [Accessed: 17-Aug-2018].

[18] Z. Kunpeng, C. Junzheng, O. Wenmin, S. Baokui, G. Chong, and L. Hongzhou, "Design of a $6250 \mathrm{~A} / \pm 800 \mathrm{kV}$ UHVDC converter valve," IET International conference of AC DC Power Transmission, (2017).

[19] D. Wu, U. Astrom, Z. Liu, L. Gao, W. Ma, Z. Su, "External insulation design of converter stations for Xiangjiaba-Shanghai $\pm 800 \mathrm{kV}$ UHVDC project," Conference on Power System Technology (2010).
[20] J. Wang, H. Wu, Z. Deng, Z. Peng and J. Liao, "E-field distribution analysis on three types of converter double valve in $800 \mathrm{kV}$ valve hall", IEEE International Conference on Properties and Applications of Dielectric Materials (ICPADM), (2015).

[21] M. S. Kher, S. Bindu, "Electromagnetic modelling of three phase UHVDC valve casing", IEEE Annual India Conference (INDICON), (2013).

[22] Williams T., Tran N., Rands J., Dantam N.T., "Augmented, Mixed, and Virtual Reality Enabling of Robot Deixis" in Virtual, Augmented and Mixed Reality: Interaction, Navigation, Visualization, Embodiment, and Simulation. VAMR 2018. Lecture Notes in Computer Science, vol 10909. Springer, Cham.

[23] E. Ackerman, "See Straight Through Walls by Augmenting Your Eyeballs With Drones" [Online]. Available:

https://spectrum.ieee.org/automaton/robotics/drones/seestraight-through-walls-by-augmenting-your-eyeballswith-drones [Accessed: 31-Aug-2018].

[24] J. Häfner and B. Jacobson, "Proactive Hybrid HVDCbreakers - A key innovation for Reliable HVDC grid", Cigré symposium, (2011).

[25] X. Pei, O. Cwikowski, A. C. Smith and M. Barnes, "Design and Experimental Tests of a Superconducting Hybrid DC Circuit Breaker," IEEE Transactions on Applied Superconductivity, vol. 28, no. 3, (2018).

[26] L. Ängquist, S. Norrga and T. Modéer, "A new dc breaker with reduced need for semiconductors," European Conference on Power Electronics and Applications (EPE'16 ECCE Europe), (2016).

[27] T. Erikksson, M. Backman, S. Halen, "A low loss mechanical HVDC breaker for HVDC Grid applications", CIGRE (2014).

[28] S. Tokoyoda et al., "Interruption characteristics of vacuum circuit breaker and the application to DCCB," IET International Conference on AC and DC Power Transmission (2017).

[29] CIGRE WG B4.60, "Designing HVDC grids for optimal reliability and availability performance", Technical brochure, December 2017.

[30] AMAT. Fault Current Limiter Technology, 2016. [Online].Available: http://www.appliedmaterials.com/en ergy/fault-current-limiters.

[31] G. Escamez, J. Vialle, C. Bruzek, V. Große, M. Bauer and P. Tixador, "Numerical Investigations of ReBCO Conductors With High Limitation Electric Field for HVDC SFCL," IEEE Transactions on Applied Superconductivity, vol. 28, no. 4, (2018), Art no. 5602705.

[32] P. Tixador, J. Vialle and A. Badel, "Operation of an SCFCL at $65 \mathrm{~K}$," in IEEE Transactions on Applied Superconductivity, vol. 28, no. 4, (2018) Art no. 5601005.

[33] A. Hobl, W. Goldacker, B. Dutoit, L. Martini, A. Petermann and P. Tixador, "Design and Production of the ECCOFLOW Resistive Fault Current Limiter," in IEEE Transactions on Applied Superconductivity, vol. 23, no. 3, (2013), Art no. 5601804. 